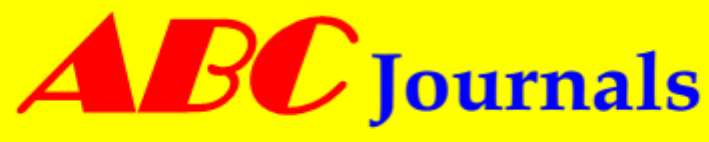

A new domain in research publishing

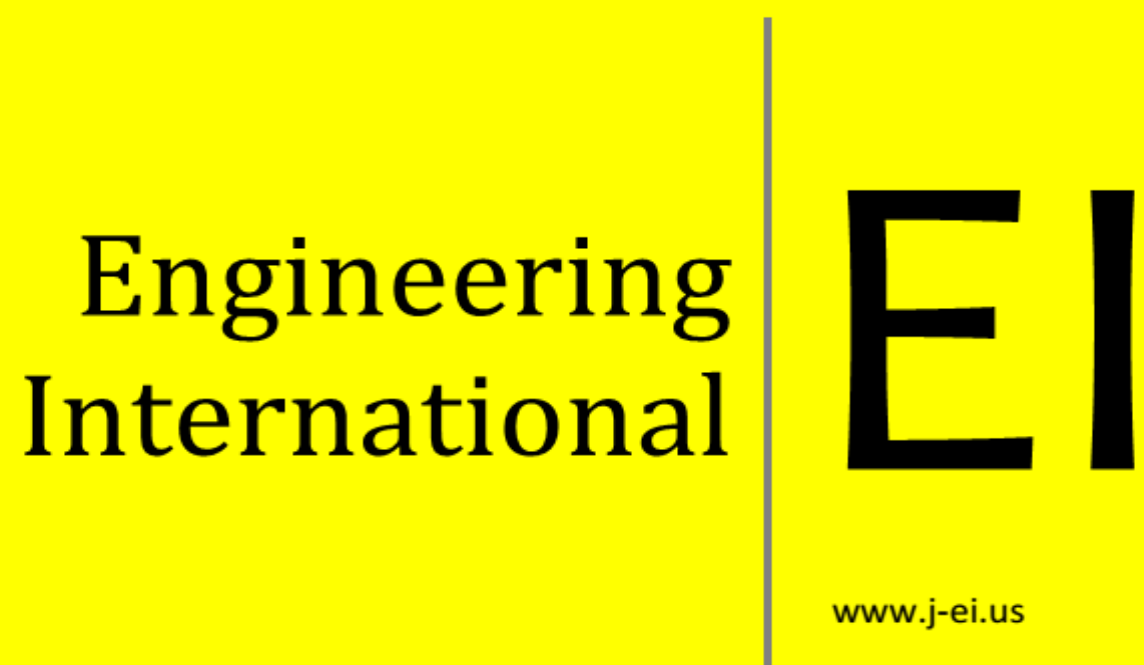

Asian Business Consortium 


\title{
Mechanical Characterization of Banana/Sisal Fibre Reinforced PLA Hybrid Composites for Structural Application
}

\author{
Ravi Ranjan, P K Bajpai, \& R K Tyagi
}

Amity University, Noida, U.P, India

\begin{abstract}
Advanced technology emergence in the field of petrochemical-based polymers has brought many benefits to mankind. It is validating that the ecosystem is considerably disturbed and damaged as a result of the nondegradable plastic materials used for disposable items. This paper relates the use of hybrid bio-composites, which is eco-friendly and easily degradable. Previous literature related to hybrid bio-composites proves its eco-friendly and excellent degradable properties. In this paper, banana and sisal fibers were selected to execute the hybrid bio-composite preparation with poly lactic as its matrix. Specimens were made with and without fibre treatment and their mechanical properties like tensile, flexural and impact were evaluated as per the standard test procedures. The test results obtained evident that the treated fibers having the best mechanical properties than pure PLA and untreated fibre bio-composites. The chemical treatment also improved fiber matrix interaction by removal of lignin and hemicellulose, which led to the better incorporation of fiber with the matrix. The SEM micrographs of untreated banana/sisal fibre reinforced PLA bio-composites and treated banana/sisal fibre reinforced PLA bio-composites clearly indicated the extent of the fiber-matrix interface adhesion.
\end{abstract}

\section{INTRODUCTION}

The worldwide automotive production rate is increasing and estimated to reach 76 million cars annually by 2020. Limited petroleum resources will increase petroleum-based products' prices in the near future. It is estimated that a $25 \%$ reduction in car weight would be equivalent to saving 250 million barrels of crude oil. Composite has emerged as the solution of attaining high strength to weight ratio. Advanced technology in the field of petrochemical-based polymers has brought many benefits to mankind. It is becoming more evident that the ecosystem is considerably disturbed and damaged as a result of the non-degradable plastic materials for disposable items (Weng 2006). There is a growing urgency to convert agricultural by products and surpluses of the crops into new, profitable products. The need to develop technology allied with environmental preservation has created a renewed interest in the scientific world to study the viability of using natural fibres as reinforcement agents in biopolymer matrices. Such fibre based composites 
normally show good mechanical properties and reduce the dependence on materials obtained from non renewable source (fossil-based), leading to both economic and environmental benefits. The advantages of natural fibres over synthetic or manmade fibres such as glass or carbon are low cost, low density, acceptable specific strength properties, ease of separation, carbon dioxide sequestration and biodegradability.

Natural fibres may be obtained either from plants or animals. Plant based fibres such as hemp, kenaf, flax; bamboo and sisal have gained many commercial successes in automotive applications. Further research on the feasibility study to assess the potential application of natural fibres as reinforcing sheet moulding compounding materials for the use in building applications is also gaining much commercial interest (Hapuarachchi, 2007). Fibres obtained from animal sources like silk (Scheibel 2004) and wool (Blicblau, 1997) are also used as reinforcing agents. A study by Sim et al. (Sim, 2010), on the dynamic mechanical and thermal properties of red algae fibre reinforced PLA, bio-composite show improved mechanical strength with increasing fibre loading (Mohanty, 2002). Biodegradable polymers like PLA, cellulose esters, poly-hydoxy-alkaoates (PHA) and starch polymers can be reinforced with these bio based fibres to produce environmentally beneficial "green composites" (Mohanty, 2000). PLA is a natural resourced thermoplastic polymer which can be produced with a capacity of over 140,000 tonnes per year. Increased availability of PLA and the competing petroleum costs are the key driving factors for the polymer scientists to produce novel PLA based biocomposites that can compete with petroleum based plastics available in the market. Biodegradable polymers, such as poly lactic acid (PLA), have been the subject of many studies over the past decade because of the increasing need to reduce petroleum-based plastic pollution. PLA is obtained from fermented corn, has attracted considerable interest in recent years because it is being produced commercially on a large scale at a reasonable price. PLA has been used for many years in biomedical applications, such as sutures, pins, scaffolds, and drug delivery devices. In addition, PLA is used in a variety of fields, and has found applications in fast food service ware, mulch films, and grocery and composting bags, trays, and bottles. Natural fibers as reinforcements to PLA have advantages, such as low cost, renewability, biodegradability, low specific gravity, abundance, high specific strength, and nonabrasiveness (Czarnecki 1980). Therefore, bio-composites reinforced with natural fibers appear to be an alternative material to glass fiber-reinforced plastics in some technical applications. Recently, natural fiber-reinforced bio-composites have been used as automotive parts on account of their good mechanical properties and light weight. PLA is a useful material for processing car interior parts owing to its good strength and easy processability. However, it needs further development for most practical applications due to problems, such as low thermal stability and brittle characteristic (Huda, 2006). The addition of fibers or filler materials has been suggested as a means of improving the thermal and mechanical properties of PLA. In addition, the bonding between the added fiber and PLA matrix was stronger by maleated polylatide (MAPLA) (Plackett, 2004). Flax, jute and hemp are used in the thermoplastic matrix composite panels for internal structures in the automotive industry. Hemp is used to prepare sheet moulding compounds for building applications. The main drawback in using natural fibers is their hydrophilic nature, thereby causing difficulties in adhesion with the hydrophobic polymer matrix. Several investigators have studied the fibre-surface treatment methods to improve the fiber matrix adhesion characteristics. Bledzki et al. (Bledzki 2010) depicted a two step process extrusion followed by injection moulding to prepare fibre reinforced PLA based compos-ites. This approach is similar to the former studies as conducted by Gatenholm 
and Mathiasson et al. when they tried to study the influence of the processing parameters on and fibrous reinforcement of poly-hydroxybutyrate (PHB) and polyhyroxyvalerate (PHBV). Bledzki et al. compounded together PLA with endless fibres through a coating die and cooled to ambient tem-perature using a twin screw extruder, which was followed by injection moulding to prepare the final composite. Improved mechanical properties with a two step extrusion process were reported in comparison to agglomeration of the compound with twin-rotary mixer, as performed by Shibata et al. A two step extrusion process facilitates in good dispersion of fibres in the matrix and thereby improves its mechanical properties. Oksman et al. studied the reinforcement of PLA with flax fibre content of 30-40 $\mathrm{wt} \%$. The studied composite materials were manufactured with a twinscrew extruder and then compression moulded to test samples. The objective of the study was to test the processing and the material properties and compare it with more commonly used polypropylene flax fibre composites. It was found that addition of flax to the PLA matrix improved the mechanical properties; however there was no further improvement on addition of more loading of fibre possibly due to the same processing condition and fibre orientation. Very recently, van den Oever et al. studied the effect of water content in undried and dried natural fibres. The fibres evaluated were ramie, flax and cotton, containing 6-9 percentages of moisture mass in the undried state and 0.2-0.4\% mass in the dried state.

\section{MATERIALS AND METHOD}

Two types of fibre used in this work.

1. Sisal fibers are made from sisal plant leaves. The shape of sisal leaves is like sword and is about 1.5 to 2 meters tall. Sisal fibers are smooth, straight and yellow in colour. Sisal is fairly coarse and inflexible, so the sisal fibre can be long or short.

2. The banana or abaca fiber, which is from the banana plant. It is durable and resistant to sea water. Abaca, the strongest of the commercially available cellulose fibres, is indigenous to the Philippines and is currently produced in that country and in Ecuador. Availability of banana fiber is plenty in India. Untreated sisal and banana fibers are shown in figure 1.
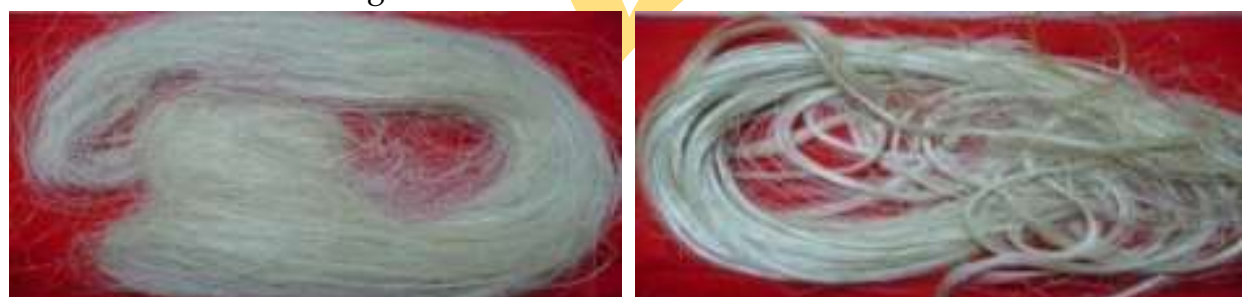

Figure 1 Untreated Sisal fibre \& Banana fibre

\section{Fiber Cleaning AND AlKali treatments}

Banana and Sisal fibers were cut into an approximate length of $20 \mathrm{~cm}$ then soaked separately in water for a week. After that, the fibers were washed with water in order to remove small barks and dirt. The fibers were dried in an oven at $60^{\circ} \mathrm{C}$ overnight, and then the fibers were carded to separate as fiber filaments. After that, the fibers were cleaned with $2 \mathrm{wt} \%$ sodium hydroxide $(\mathrm{NaOH})$ solution for $2 \mathrm{hrs}$ to eliminate hemicelluloses. The fibers were washed with water several times and dried in an oven at $60^{\circ} \mathrm{C}$ overnight. These fibers were called "cleaned fibers (CL)". 
Treating fibres with sodium hydroxide $(\mathrm{NaOH})$ at elevated temperatures, results in the removal and degradation of hemicelluloses, lignin, pectin and waxes. The removal of these materials allows the reactive hydroxyl $(\mathrm{OH})$ groups on cellulose to be exposed, allowing effective bonding between matrix and fibre or coupling agent. This debonding also allows fibrils to be released from their fibre bundles, increasing the surface area for interfacial bonding with the matrix material.

The Banana and sisal fiber was then washed several times with water containing acetic acid. Finally, the Banana and sisal fiber was washed again with distilled water and oven dried at $70^{\circ} \mathrm{C}$ until it completely dried and reached constant weight. Treated chopped sisal and banana fibers are shown in figure 2 .
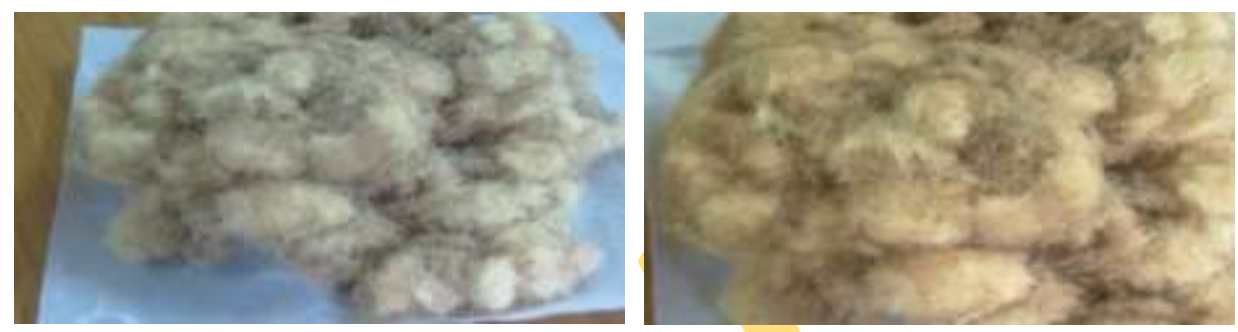

Figure 2 Treated chopped Sisal and Banana fibres

\section{MANUFACTURE OF BIO COMPOSITES}

Composites were produced by compounding chopped fibres and PLA pellets in a twinscrew extruder, and the extruded composites were then granulated for the injection moulding for the material preparation. The injection moulder melts pre-formed short fibre reinforced composite granules in a screw driven barrel, sending composite melt to the machine nozzle. It then injects a measured amount of melt into the mould. The mould unit, which has two sections, a moving and a stationary section, encapsulates the injected composite within its form in which is cooled, creating a final component. The resulting specimens were put into an oven and were annealed at different temperatures for varying time periods. The resulting composite specimens were analysed to evaluate various physical attributes, such as strength, Young's modulus, crystalline and thermal stability. The schematic fabrication process for biocomposite is shown in figure 3 .

\begin{tabular}{|c|c|c|c|c|}
\hline MATERIAL & MELT & INJECTION & MOULD & $\begin{array}{l}\text { FINAL } \\
\text { PART }\end{array}$ \\
\hline Concentration muxing & $\begin{array}{l}\text { - barrel tempersture } \\
\text { - serew speed } \\
\text { - back pressate }\end{array}$ & $\begin{array}{l}\text { - transfer point } \\
\text { - injeetion speed } \\
\text { - inuection pressture }\end{array}$ & $\begin{array}{l}\text { - motild tempersture } \\
\text { injection point } \\
\text { - hold time } \\
\text { - hold pressure }\end{array}$ & $\begin{array}{l}\text { - Mechanieal } \\
\text { properties } \\
\text { - Themial } \\
\text { paoperties }\end{array}$ \\
\hline
\end{tabular}

\section{Tensile Testing}

Figure 3 Composite parts preparation

Instron universal testing machine (UTM, model 5565) with a load cell of $5 \mathrm{kN}$, a crosshead speed of $10 \mathrm{~mm} / \mathrm{min}$, and a gauge length of $80 \mathrm{~mm}$ was used to evaluate tensile and flexural properties. The ASTM standard test method for tensile properties of fiber resin composites has the designation D 638. The tensile test specimens are shown in figure 4. 


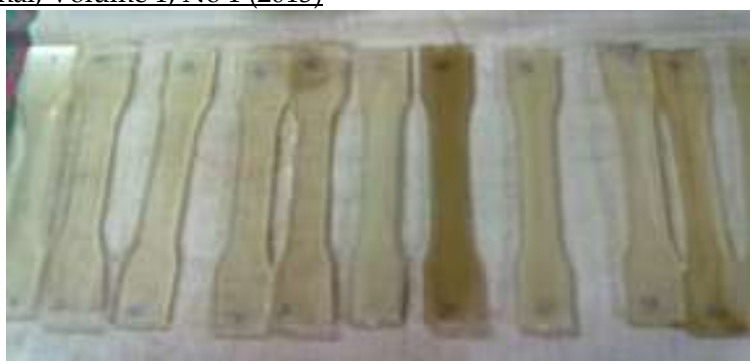

Figure 4. Tensile test specimens

\section{Flexural Testing}

The three-point bend flexural test was conducted in accordance with ASTM D 790 method. For flexural analysis the specimens of dimension $125 \mathrm{~mm} \times 10 \mathrm{~mm} \times 5 \mathrm{~mm}$ were used (figure 5). Span length was fixed at $50 \mathrm{~mm}$ and the test was conducted at the constant strain rate of $2.54 \mathrm{~mm} / \mathrm{min}$. The flexural stress was applied till the failure of the sample and load-deflection curve was obtained.

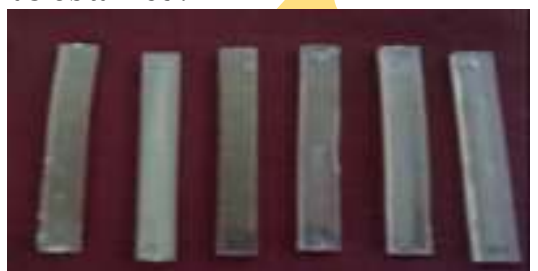

\section{Impact strength}

Figure 5. Specimens for three points bend test.

In this work Charpy impact test was used to measure the impact strength. All test samples were notched. Low velocity instrumented impact tests are carried out on composite specimens. The tests are done as per ASTM D 256 using an impact tester. For each plate corresponding to a given volume fraction, 10 specimens were machined with a $2.54 \mathrm{~mm}$ deep notch, angle of $45^{\circ}$ and a tip radius of $0.25 \mathrm{~mm}$.

\section{Scanning electron microscopy (SEM)}

A lower magnification with the optical microscope does not reveal the fine scale microstructure. Scanning electron microscopy was required to observe the fine microstructure of the tensile, flexural and impact fracture morphology of the composite samples Gold-coating of the fractured specimens was done with asputter coater (S150B) in argon gas and at $3 \mathrm{~m}$ bar.

\section{RESULTS AND Discussion}

\section{Effect of treatment on composites properties}

The mechanical properties of natural fibers vary considerably depending on the chemical and structural composition, fiber type and growth conditions. The mechanical properties of composites are influenced mainly by the adhesion between the matrix and fibers.This can be explained due to the presence of chemical treatment and modification which provided a stronger adhesion between fibers and matrix these results agree well with it. It is observed in treated composites which indicated stronger adhesion between natural fibers and (matrix, banana fibers) resulted higher tensile strength than untreated composite. Bio-composite materials with good strength properties can be produced when the fiber is uniformly dispersed and distributed in the matrix. Interaction and adhesion 
between the PLA and the banana/sisal fiber can be improved by the addition of a plasticizer, which softens the PLA matrix. The morphology of the fractured surfaces from tensile testing was also examined by scanning electron microscope (SEM).

\section{Effect of Fiber Treatment $(\mathrm{NaOH})$ on Tensile properties}

The results for tensile strength, flexural strength and impact strength of pure PLA, untreated bunana/sisal hybrid composites are shown in figure 6, 7 and 8 respectively. Based on the readings found out from the table-1, table-2 and table-3, Treated banana/sisal reinforced PLA composites $(\mathrm{NaOH})$ showed the cleanest fiber surface which has improved the interfacial bonding by providing additional sites of mechanical interlocking, which promotes more resin/fiber interpenetration at the surface. The alkaline treatment also improves the fiber surface adhesion characteristics by removing natural and artificial impurities, thereby producing a rough surface topography. It has been reported that alkali treatment leads to fiber fibrillation, breaking down of fiber bundles into smaller fibers, which increases the effective surface area available for contact with the matrix. The value of tensile modulus increased after the fiber was treated with $\mathrm{NaOH}$ concentration. It is clear that the modulus of a well-bonded composite arises from the fact that the load transfer between the fiber and matrix occurs through the strong fiber/matrix interface. The tensile modulus of the chemically treated composites exhibits higher modulus values than untreated composite. It can be seen that this is due to the presence of a strong interface between the treated fiber and matrix.

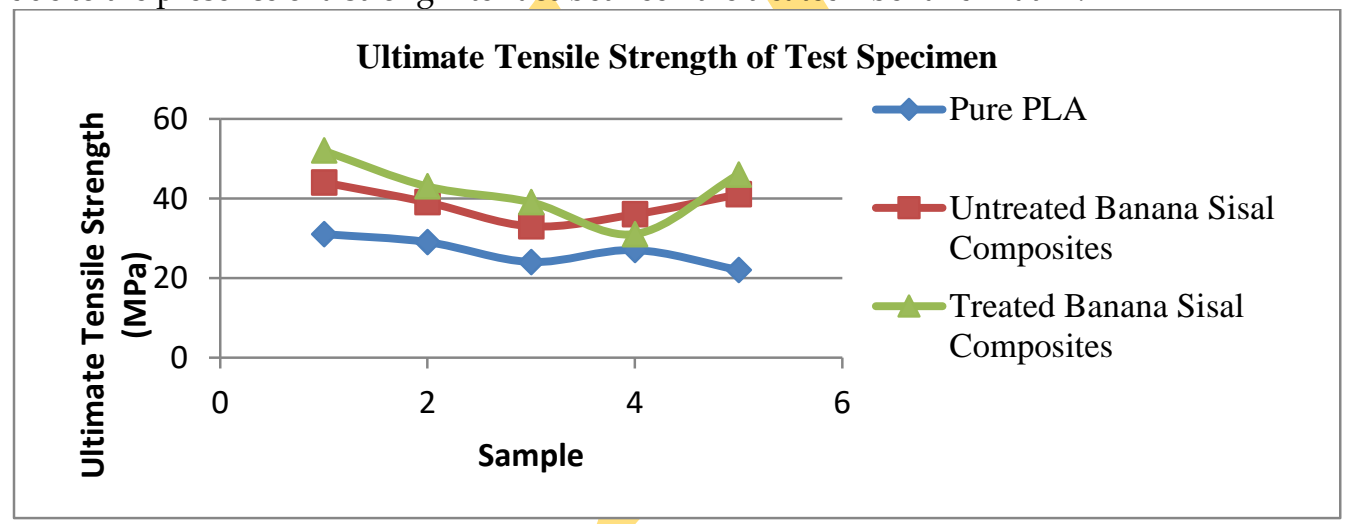

Figure 6 Tensile strength of the developed hybrid composites

\section{Effect Of $\mathrm{NaOH}$ treatment on flexural and impact properties}

Based on the readings found out from the table- 1 , table- 2 and table- 3 , Treated banana/sisal reinforced PLA composites $(\mathrm{NaOH})$ showed that The alkali treatment can cause an increase of the fibre surface free energy. The adsorption of the PLA resin on the banana/sisal fibre surface increases, which is a prerequisite condition for creating the interphases. Moreover, the alkali treatment can make the fibre surface become 'clean' due to removal of waxes, hemicelluloses, pectin and part of lignin. The removal of these substances enhances the surface roughness. Therefore, the mechanical interlocking at the interface could be improved. An inter phase can be formed in composites with thermoplastic PLA matrix due to preferential adsorption of resin components onto the surface of the fibres, resulting in a gradient of cure and mechanical properties. The fibre surface treatment before introducing the matrix material can modify the interphase region and alter the adhesion between the fibre and the matrix. Flexural strength and flexural modulus was observed, more in Treated banana/sisal reinforced PLA composites $(\mathrm{NaOH})$ compare to well with untreated composites. 


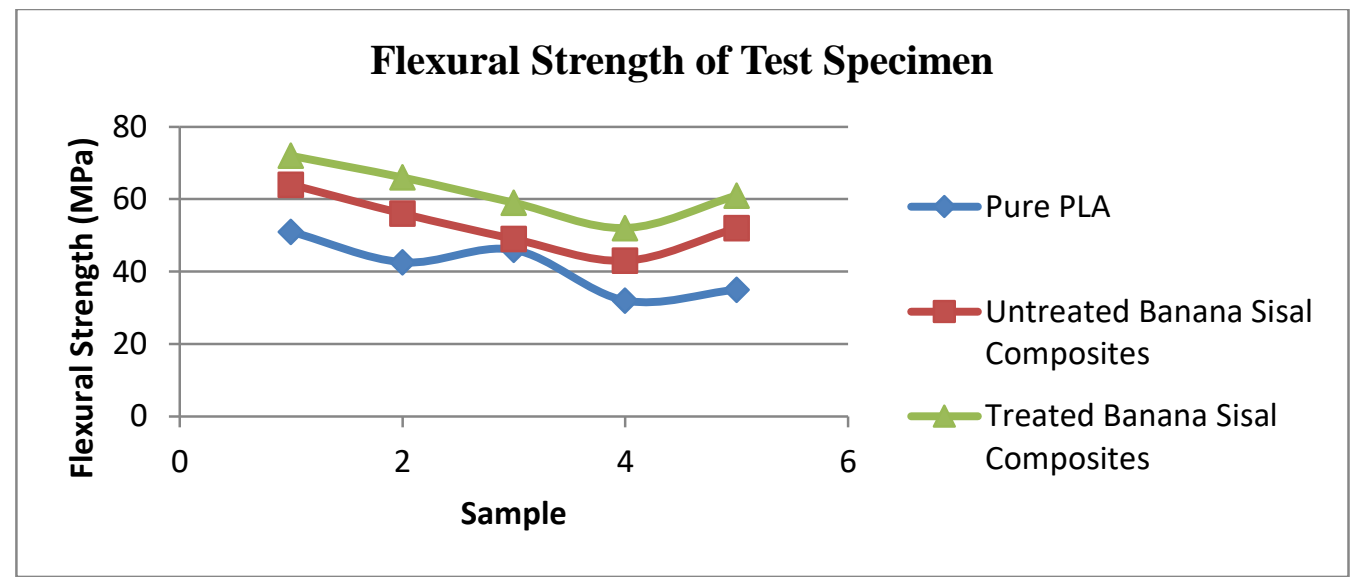

Figure 7 Flexural strength of the developed hybrid composites

It is clear that the scatter on the measured values of the impact strength of the in Treated banana/sisal reinforced PLA composites $(\mathrm{NaOH})$ is quite. The impact resistance of fibre composites is highly influenced by the interfacial bond strength.

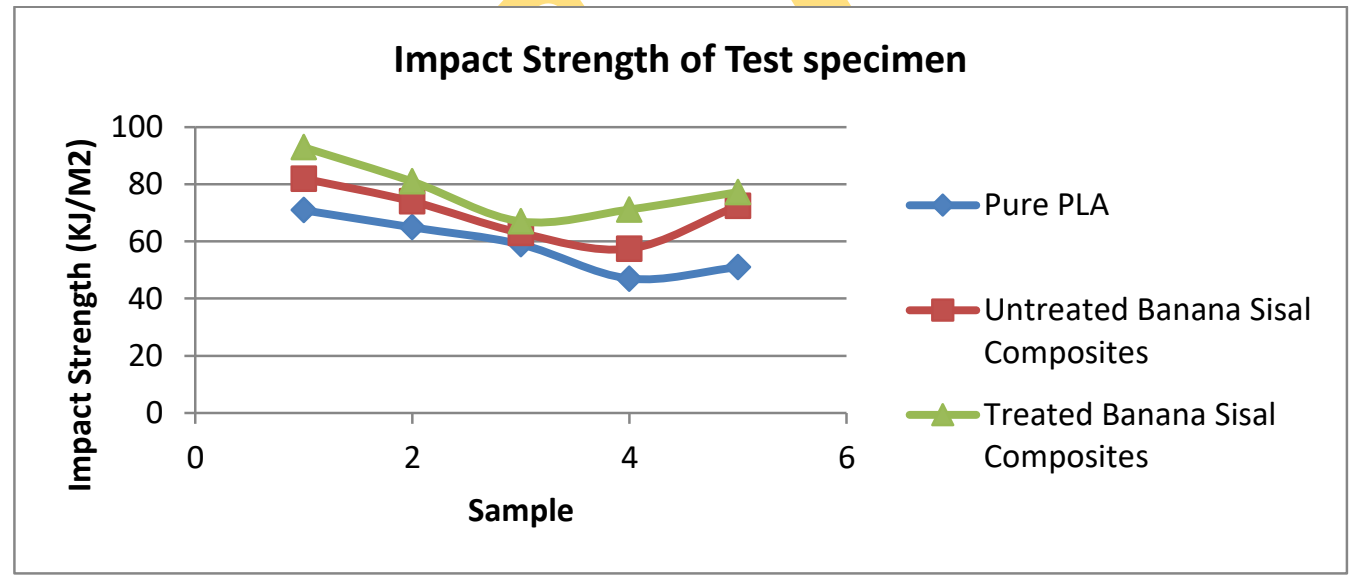

Figure 8 Impact of the developed hybrid composites

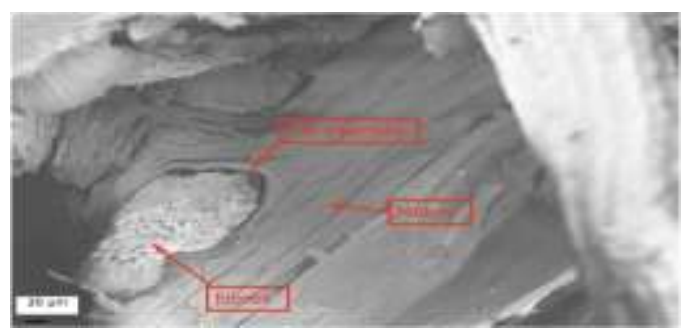

Figure 9 SEM image of untreated banana/sisal hybrid composite

Scanning electron microscopy (SEM) provides an excellent technique for examination of surface morphology of fibers and fracture surfaces of fiber composites. The SEM Micrograph of the surface of untreated banana/sisal reinforced PLA composites. Figure.9 shows 
that there was no interfacial adhesion between fibre and matrix which was found in untreated banana/sisal reinforced PLA composites Figure.10 shows the fracture surface of the untreated banana/sisal reinforced PLA composites with $30 \mathrm{wt} \%$ of fiber content. It is possible to see from the microscopy picture that there are many fibers pulled out.
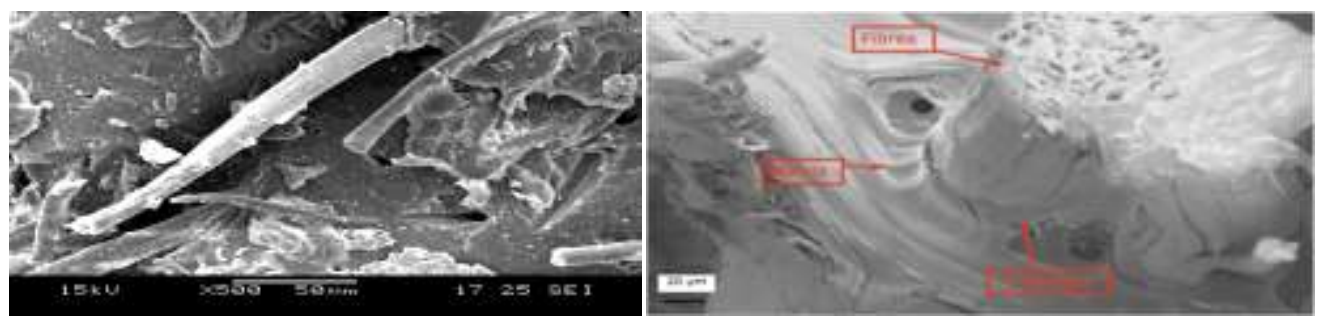

Figure.10 Fibre Pull out and Fibre matrix adhesion

Besides, the fiber surfaces are shown clean which indicated poor adhesion between the fibers and the PLA matrix. Figure 14 shows that there was good interfacial adhesion between fibre and matrix which was found in treated banana/sisal reinforced PLA composites there by strength of composites will increase.

\section{Conclusions}

This study demonstrated that banana/sisal fibre reinforced PLA biocomposites with good mechanical properties could be developed using banana/sisal fiber as a reinforce, and PLA as a matrix. The results of the study revealed that

- Sodium hydroxide fibre treatment improves the compatibility between the PLA matrix and banana/sisal fibre.

- The tensile strength properties of the treated banana/sisal fibre reinforced PLA biocomposites materials were significantly higher than those of untreated banana/sisal fibre reinforced PLA biocomposites.

- It is believed that the fibre treatment improved the interfacial interaction, thus resulting in good strength and stiffness of the biocomposites materials.

- The SEM micrographs of untreated banana/sisal fibre reinforced PLA biocomposites and treated banana/sisal fibre reinforced PLA biocomposites clearly indicated the extent of the fiber-matrix interface adhesion.

- It has been noticed that the mechanical properties of the banana and sisal fiber composites such tensile strength, flexural strength, impact strength etc. of the composites are also greatly influenced by the fibre treatments.

- The fracture surfaces study of banana and sisal fiber reinforced PLA composite after the tensile test, flexural test and impact test has been done. From this study it has been concluded that the poor interfacial bonding is responsible for low mechanical properties.

- Thus we conclude that the systematic and persistent research in the future will increase the scope and better future for banana and sisal fiber reinforced PLA composite.

- The alkaline treatment of fiber gave the better tensile strength and flexural strength of the composite.

- The chemical treatment also improved fiber matrix interaction by removal of lignin and hemicellulose, which led to the better incorporation of fiber with the matrix.

- The Construction Material Subcategory includes product applications containing biobased adhesives, such as plywood and finger jointed lumber; oriented strand board, medium density fiberboard, and hardboard; engineered wood building 
components, e.g., laminated beams, trusses, finger jointed lumber, oriented strand lumber; moldings and trim; and decorative composites.

- Construction products include round wood; lumber; composites; and plastic-wood composite lumber and panels such as plywood, oriented strand board, medium density fiberboard, and hardboard that contain agricultural or wood-based materials.

- Bio-composite components can be shaped to have high geometric stiffness to meet deflection limits while minimizing material use.

- Recent work has shown that the properties of hybrid natural/glass composites with only $\sim 6 \mathrm{wt} . \%$ glass fiber loading have been found to be an effective way to improve mechanical properties and dimensional stability (moisture, temperature, etc.) of the composite.

\section{SCOPE FOR FUTURE WORK}

There is a very wide scope for future scholars to explore this area of research. The possibility of improving the outdoor properties of natural fiber-reinforced composites should be studied. Although many authors have done several pre-treatment of natural fibers in order to improve the interfacial adhesion between the fiber and the matrix, thus improving the mechanical properties of the resulting composite, quite a few studies have been done on how to specifically reduce the water absorption in natural fiber-reinforced composites.

\section{REFERENCES}

Arib RMN, Sapuan SM, Hamdan MAMM, Paridah MT, Zaman HMDK. Polym Polym Compos. 2004; 12-341.

Bajpai PK, Singh I, Madaan J, International Journal of Materials Engineering Innovation, 2012, 3, 247-258.

Bajpai PK, Singh I, Madaan J, Journal of Natural Fibers, 2013, 10, 244-256.

Bajpai PK, Singh I, Madaan J, Journal of Reinforced Plastics and Composites, 2012, 31, 17121724.

Bajpai PK, Singh I, Madaan J, Materials and Design, 2012, 35, 596-602.

Barbosa V, Ramires EC, Razera IAT, Frollini E. Indust Crops Prod. 2010; 32-305.

Bledzki AK, Jaszkiewicz A, Scherzer D. Compos Part A. 2009; 40-404.

Bledzki AK, Jaszkiewicz A. Comp Sci Technol. 2010; 70-1687.

Blicblau AS, Coutta RSP, Sims A. J Mater Sci Letter. 1997; 16-1417.

Brahim SB, Cheikh RB. Compos Sci Technol. 2007; 67-140.

Brahmakumar M, Pavithran C, Pillai RM. Compos SciTech. 2005; 65-563.

Chattopadhyay SK, Khandal RK, Uppaluri R, Ghoshal AK. J Appl Polym Sci. 2010; 3-119.

Chow W, Lok S. J Therm Anal Calorim. 2009; 95:627-32.

Czarnecki L, White JL. J Appl Polym Sci. 1980;25:1217-44.

Gatenholm P, Kubat J, Mathiasson A. J Appl Polym Sci. 1992; 45-1667.

Gatenholm P, Mathiasson A. J Appl Polym Sci. 1994; 51-1231.

Hapuarachchi TD, Ren G, Fan M, Hogg PJ, Pejis T. App Compos Mater. 2007; 14-251.

Holbery J, Houston D. J Miner Metal Mater Soc. 2006; 58-80.

Huda MS, Drzal LT, Misra M, Mohanty AK, J Appl Polym Sci.2006;102: 4856-69.

Huda MS, Drzal LT, Mohanty AK, Misra M. Com-pos Sci Technol. 2006; 66:1813-24.

Huda MS, Mohanty AK, Drzal LT, Schut E, Misra M. J Mater Sci. 2005; 40:4221-9.

Jiang L, Chen F, Qian J, Huang J, Wolcott M, Liu L, Zhang J. Indust Eng Chem Res. 2010; 49-572.

Krishnaprasad R, Veena NR, Maria HJ, Rajan R, Skrifvars M, Joseph K. J Polym Environ. 2009; 17-109.

Lee SH, Wang S. Appl Sci Manufact . 2006; 37(1):80-91.

Lu Y, Weng L, Cao X. Carbohydrate Polymers.2006; 63, 198-204. 
Mohanty AK, Misra M, Drzal LT, Selke SE, Hinrichsen G. Macromol Mater Eng. 2000; 276-1.

Mohanty AK, Misra M, Drzal LT. J Polym Environ. 2002; 10:19-26.

Mohanty AK, Misra M, Drzal LT. J Polym Environ. 2002; 10-19.

Mohanty S, Varma SK, Nayak SK. Compos Sci Technol. 2006; 66-538.

Oksman K, Skrifvarsb M, Selinc JF. Compos Sci Technol. 2003; 63-1317.

Plackett D. J Polym Environ. 2004; 12: 131-8.

Rao KMM, Prasad AVR, Babu MNVR, Rao KM, Gupta AV. J Mater Sci. 2007; 42-3266.

Scheibel T. 2004; http:/ /www.microbialcellfactories.com/content/3/1/14.

Shen L, Worrell E, Patel M. Biofuels Bioprod Bioref. 2009; 4-25.

Shibata M, Ozawa K, Teramoto N, Yosomiya R, Takeishi H. Macromol Mater Eng. 2003; 288-35.

Sim KJ, Han SO, Seo YB. Macromol Res, 2010; 18-5.

Singh I, Bajpai PK, Malik D, Madaan J, Bhatnagar N, Advanced Materials Research, 2012, 410, 102-105.

Summerscales J, Dissanayake N, Virk A, Hall W. Part2-Compos Part A. 2010; 41-1336.

Summersclales J, Dissanayake NPJ, Virk AS, Hall W. Part1-Compos Part A. 2010; 41-1329.

Van den Oever MJA, Beck B, Mussig J. Compos A. 2010; 41-1628.

Wang W, Sain M, Cooper PA. Polym Degrad Stab. 2005; 90:540-545.

Asian Business Consortium is an independent research house committed to publishing and delivering superior, Peer-reviewed standard research 